\title{
Correction to: Optimization of cell/tissue culture of Linum persicum for production of lignans derivatives including Podophyllotoxin
}

\author{
Mina Esfandiari ${ }^{1,2} \cdot$ Mohsen Sharifi $^{1} \cdot$ Farzaneh Mohamadyar-Toupkanlou ${ }^{3} \cdot$ Hana Hanaee-Ahwaz ${ }^{4}$. \\ Morteza Yousefzadi ${ }^{5} \cdot$ Azizollah Jafari $^{6} \cdot$ Simzar Hosseinzadeh $^{7} \cdot$ Masoud Soleimani $^{8}$
}

Published online: 7 February 2018

๑) Springer Science+Business Media B.V., part of Springer Nature 2018

\section{Correction to: \\ Plant Cell, Tissue and Organ Culture (PCTOC) \\ https://doi.org/10.1007/s11240-017-1360-y}

There was a spelling error in the seventh author's first name in the initial online publication. The original article has been corrected.

The original article can be found online at https://doi.org/10.1007/ s11240-017-1360-y.

\section{Mohsen Sharifi}

msharifi@modares.ac.ir

1 Department of Plant Biology, Faculty of Biological Sciences, Tarbiat Modares University, Tehran 14115-154, Iran

2 Department of Nanotechnology and Tissue Engineering, Stem Cell Technology Research Center, Tehran, Iran

3 Department of Chemical Engineering, Faculty of Chemical Engineering, Tarbiat Modares University, Tehran, Iran

4 Stem Cell Biology Department, Stem Cell Technology Research Center, Tehran, Iran

5 Department of Marine Biology, Hormozgan University, Bandar Abbas, Iran

6 Department of Phytochemistry, Faculty of Science, Yasouj University, Yasouj, Iran

7 Department of Tissue Engineering and Regenerative Medicine, School of Advanced Technologies in Medicine, Shahid Beheshti University of Medical Sciences, Tehran, Iran

8 Department of Hematology, Faculty of Medicine, Tarbiat Modares University, Tehran, Iran 